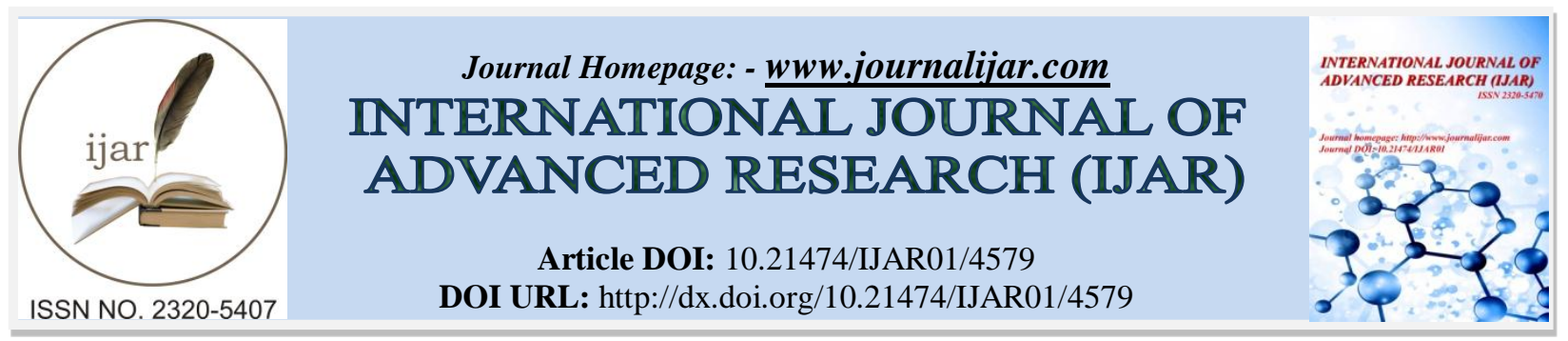

\title{
RESEARCH ARTICLE \\ COMPARISON OF CONCENTRIC AND ECCENTRIC EXERCISE INTERVENTION IN PATIENTS WITH SUBACROMIAL IMPINGEMENT SYNDROME.
}

\author{
"Suresh. $\mathbf{J}^{1}$, Vinitha.S ${ }^{2}$ and Sivakumar. V. P. $\mathbf{R}^{3}$. \\ 1. Assistant Professor, SRM college of Physiotherapy. \\ 2. Student, SRM college of Physiotherapy. \\ 3. Dean, SRM college of Physiotherapy.
}

\section{Manuscript Info}

Manuscript History

Received: 23 April 2017

Final Accepted: 25 May 2017

Published: June 2017

Key words:-

Wax bath therapy, Eccentric exercise and concentric exercises

\section{Abstract}

Background: There are many treatments given for subacromial impingement syndrome which includes Anti-inflammatory Drugs, Massage, However, studies involving wax bath therapy and concentric and eccentric exercise for management of subacromial impingement syndrome are limited to this date. Objective: To find out and compare the effects of concentric and eccentric exercises in subjects with subacromial impingement syndrome. Study design: Quasi experimental study design, Comparative type. Procedure: 5subjects were treated with wax bath therapy with eccentric exercise and other 5 were treated with wax bath therapy with concentric exercise in age group 25 - 50 years of both male and female. Outcome measures : Neumeric Pain Rating Scale (NPRS) and Shoulder Pain And Disability Index(SPADI) . Results: The results of this study were analyzed in SPSS software gives $p>0.05$ which shows that there is a significant difference in the pre and post test values of Shoulder Pain and Disability index of Group A treated with wax bath and concentric exercises whereas Group B subjects treated with wax bath therapy and eccentric exercises show a significant improvement in pain, Range of motion and Shoulder Pain and Disability index for. Conclusion: There is no significant difference between concentric and eccentric exercises training among patients with Subacromial impingement syndrome.

Copy Right, IJAR, 2017,. All rights reserved.

\section{Introduction:-}

Shoulder impingement has been defined as compression and mechanical abrasion of the rotator cuff structures as they pass beneath the coraco acromial arch during elevation of the arm. ${ }^{1,2}$. Shoulder impingement syndrome and rotator cuff tendinitis are considered to be the most frequent cause of intrinsic shoulder pain and disability. ${ }^{1}$

The rotator cuff is a series of four muscles that surround the ball of the shoulder (humeral head). The sub acromial bursa sits over the top of the cuff, allowing for the cuff tendons to slide near the roof of the shoulder without normal the humeral head gets closer to the acromion when the shoulder is moved, particularly as reaching overhead.Multiple theories exist to the primary etiology of shoulder impingement, including anatomic abnormalities of the coraco acromial arch or humeral head ${ }^{10,11}$;"tension overload," ischemia, or degeneration of the rotator cuff 
tendons $^{12-14}$; and shoulder kinematic abnormalities ${ }^{15,16}$. Alterations in scapular position and motion occur in $68-$ $100 \%$ of patients with shoulder injuries.

Subacromial impingement syndrome is a painful compression of the supraspinatus tendon, the sub acromial- sub deltoid bursa, and the long head of the biceps tendon between the humeral head and the anterior portion of the acromion occurring during abduction and forward elevation of the internally rotated arm (Neer 1972). Shoulder impingement accounts for 44 to $65 \%$ of shoulder complaints during physician visit. Primary compressive disease or impingement is a direct result of compression of the rotator cuff tendons between the humeral head and the overlying anterior third of the acromion, coraco acromial ligament, coracoid or acromial clavicular joint.

Impingement is traditionally divided into external impingement and internal impingement groups, with the external impingement group being subdivided into primary and secondary subgroups. Primary external impingement implies abnormalities of the superior bony structures, leading to encroachment of the sub acromial space from above. An abnormally shaped acromion is often the cause, but an acromial bony spur may occur in older age groups . ${ }^{7}$

Neer described sub acromial impingement syndrome as a distinct clinical entity and hypothesis that the rotator cuff is impinged upon by the anterior one third of the acromion, the coracoacromial ligament and the acromioclavicular joint rather than by merely the lateral aspect of the acromion. He also suggested that the part of the rotator cuff that is impinged upon is at the insertion of the supraspinatus tendon on the greater tuberosity (the impingement zone). The clinical diagnosis of impingement syndrome is commonly based on findings called the impingement sign and the impingement test (Neer \& Welsh 1977). The patient's history typically includes pain at night and positional discomfort called 'painful arc' (Calvert 1997). The clinical presentation may be confusing, and it is important to differentiate sub acromial impingement syndrome from other conditions that may cause symptoms in the shoulder. The third stage is represented by progressive impairment due to degeneration and rupture of the supraspinatus tendon. With further impingement wear, incomplete or complete tears of the rotator cuff and biceps lesion occur. In general affected patients are older than 40 years. This stage is associated with osseous changes at the undersurface of the acromion with bone appositions directed anteriorly inside the coraco acromial ligament, laterally, and caudally and changes at the greater tuberosity with cyst formation, bone apposition, and increased bone sclerosis. Later bone changes include narrowing of the acromio humeral distance and ascent of the humeral head in relation to the glenoid (Neer 1972)Shoulder impingement would have decreased scapular upward rotation, scapular posterior tipping, and humeral lateral rotation, as well as increased scapular medial (internal) rotation during humeral elevation. Subjects with symptoms of shoulder impingement would have increased upper trapezius muscle EMG activity and decreased lower trapezius and serratus anterior muscle EMG activity during humeral elevation. There is a common opinion that painful shoulder exercises should be avoided in the treatment of painful impingement syndrome in the shoulder.

\section{Methodology:- STUDY DESIGN STUDY TYPE STUDY SETTING}

\section{SAMPLING METHOD SAMPLE SIZE}

Inclusion Criteria of the study are as follows:-

Subjects of age group 30-50 years.

Both male and female

Numeric pain rating scale $<7$

Neer impingement test - Positive.

\author{
Exclusion Criteria of the study are as follows:- \\ Cervical or thoracic surgery. \\ Shoulder dislocations. \\ Fracture. \\ Rotator cuff tear
}

\author{
: Quasi Experimental Pilot study \\ : Comparative study. \\ : SRM Medical College Hospital and Research Centre \\ SRM University, Kattankulathur \\ : Convenient sampling \\ : 10subjects
}


Medical condition that precluded them from performing resisted exercise.

Based on the inclusion and exclusion criteria an informed consent was obtained after explaining clearly about the treatment protocol. A total of 10 subjects were taken conveniently and was divided into two groups GROUP A and GROUP B with 5 subjects in each group.

GROUP A (5 subjects) was given wax bath and concentric exercises for a period of 4 weeks. GROUP B (5 subjects) was given wax bath and eccentric exercises for a period of 4 weeks. Before and after the study duration Numeric Pain Rating Scale (NPRS) and Shoulder Pain And Disability Index (SPADI) was used for assessment.

Each individual in this group received wax bath and concentric exercise for shoulder abduction. The patient was asked to do 10 repetitions with a rest periods in between the sets. Three sets were done and the process was repeated for 4 weeks. Before starting the treatment the subjects was assessed carefully and an informed consent was taken. Wax bath is given.

\section{Group-A Concentric Exercises:-}

Subjects in the group were given exercise in standing position using Theraband in 90 degrees shoulder abduction performed for 10 times per set and 3 sets per session in one day for four weeks .

\section{Group-B:-- Eccentric Exercises:-}

Subjects in the group were given exercise in standing position using Theraband in 90 degrees shoulder abduction performed for 10 times per set and 3

Table 1:- Comparison Of Pre And Post Test Values Of Range Of Motion Of Shoulder Abduction, Muscle Strength, Muscle Power, Numerical Pain Rating Scale And Shoulder Pain And Disability Index Scores Among Group-A Subjects Treated With Concentric Exercise And Wax Therapy

\begin{tabular}{|c|c|c|c|c|c|}
\hline S.NO & & Mean & SD & $\mathrm{T}$ value & $P$ value \\
\hline & Pre ROM Shoulder Abduction & 50.00 & 14.58 & & \\
\hline \multirow[t]{2}{*}{1} & Post ROM Shoulder Abduction & 56.20 & 13.41 & & \\
\hline & & & & 2.018 & $0.114 \mathrm{NS}$ \\
\hline & Pre MUSCLE STRENGTH & 47.00 & 15.25 & & \\
\hline & & & & \multirow[t]{2}{*}{1.826} & \\
\hline \multirow[t]{2}{*}{2} & Post MUSCLE STRENGTH & 52.00 & 18.91 & & \\
\hline & & & & & $0.142 \mathrm{NS}$ \\
\hline & Pre MUSCLE POWER & 3.200 & 0.447 & & \\
\hline & & & & \multirow[t]{2}{*}{1.633} & \\
\hline \multirow[t]{2}{*}{3} & Post MUSCLE POWER & 3.60 & 0.548 & & \\
\hline & & & & & $0.178 \mathrm{NS}$ \\
\hline & Pre NPRS SCORE & 6.40 & 0.548 & & \\
\hline \multirow[t]{3}{*}{4} & & & & \multirow[t]{2}{*}{2.746} & \multirow[t]{2}{*}{$0.052 \mathrm{NS}$} \\
\hline & Post NPRS SCORE & 5.00 & 0.707 & & \\
\hline & Pre SPADI SCORE & 38.488 & 13.799 & & \\
\hline \multirow[t]{2}{*}{5} & & & & \multirow[t]{2}{*}{8.861} & \multirow[t]{2}{*}{$0.001 * *$} \\
\hline & Post SPADI SCORE & 25.628 & 12.794 & & \\
\hline
\end{tabular}

$\mathrm{P}>0.05 \mathrm{P}<0.05$

This table shows that there is no Statistical Significant difference between Pre and Post test in Shoulder Abduction, Muscle Strength, Muscle Power and Numerical pain Rating Scale Score among Group A subjects treated with Wax therapy and Concentric exercises.

This table shows that there is a statistical significant difference between pre and post test values of the Shoulder Pain and Disability Index Score among Group A subjects. sets per session. 
Table 2:- Comparison Of Pre And Post Test Values Of Rom Shoulder Abduction, Muscle Strength, Muscle Power, Numeric Pain Rating Scale And Shoulder Pain And Disability Index Scores Among Group-B Subjects Treated With Eccentric Exercise And Wax.

\begin{tabular}{|c|c|c|c|c|c|}
\hline S.NO & & Mean & SD & T value & $\mathrm{P}$ value \\
\hline & Pre ROM Shoulder & \multirow[t]{2}{*}{60.00} & 12.247 & & \multirow{3}{*}{0.025} \\
\hline & Abduction & & & \multirow{4}{*}{3.498} & \\
\hline & & & & & \\
\hline \multirow[t]{6}{*}{1} & & & & & \\
\hline & Post ROM Shoulder & \multirow[t]{2}{*}{66.60} & \multirow[t]{2}{*}{14.415} & & \\
\hline & Abduction & & & & \\
\hline & Pre MUSCLE & \multirow[t]{2}{*}{47.00} & 19.558 & & \\
\hline & STRENGTH & & & & \multirow[t]{2}{*}{0.144} \\
\hline & & & & 1.813 & \\
\hline \multirow[t]{5}{*}{2} & & & & & \\
\hline & Post MUSCLE & \multirow[t]{2}{*}{52.80} & \multirow[t]{2}{*}{19.930} & & \\
\hline & STRENGTH & & & & \\
\hline & Pre MUSCLE POWER & & 0.894 & & \\
\hline & & 3.400 & & & \\
\hline \multirow[t]{4}{*}{3} & & & & 0.000 & 1.000 \\
\hline & Post MUSCLE & \multirow[t]{2}{*}{3.40} & \multirow[t]{2}{*}{0.548} & & \\
\hline & POWER & & & & \\
\hline & Pre NPRS SCORE & \multirow[t]{2}{*}{6.00} & 0.707 & & \\
\hline \multirow[t]{4}{*}{4} & & & & & \\
\hline & & & & 3.674 & 0.021 \\
\hline & Post NPRS SCORE & 4.20 & 1.095 & & \\
\hline & Pre SPADI SCORE & 42.918 & 11.634 & & \\
\hline \multirow[t]{2}{*}{5} & & & & \multirow[t]{2}{*}{6.950} & \multirow[t]{2}{*}{0.002} \\
\hline & Post SPADI SCORE & 30.256 & 13.743 & & \\
\hline
\end{tabular}

$\mathrm{P}>0.05 \mathrm{P}<0.05$

This table shows that there is no Statistical Significant difference between Pre and Post test in Muscle Strength, Muscle Power among Group A subjects treated with Wax therapy and Concentric exercises.

This table shows that there is a statistical significant difference between pre and post test values of Shoulder Pain and Disability Index Score, Numerical Pain Rating scale, Range of Motion Abduction among Group A subjects.

Table 3:- Comparison Of Post Test Values Of Range Of Motion Shoulder Abduction, Muscle Strength, Muscle Power, Nprs And Spadi Score Between Group-A Subjects Treated With Concentric Exercise And Wax And Group-B Subjects Treated With Eccentric Exercise And Wax.

\begin{tabular}{|c|c|c|c|c|c|c|}
\hline S.NO & & & Mean & SD & $\mathrm{T}$ value & $P$ value \\
\hline & \multirow[t]{2}{*}{ Group A } & Post ROM shoulder & \multirow[t]{2}{*}{56.20} & \multirow[t]{2}{*}{13.405} & & \\
\hline & & Abduction & & & & \\
\hline \multirow[t]{5}{*}{1} & & & & & 1.181 & $0.271 \mathrm{NS}$ \\
\hline & & Post ROM Shoulder & \multirow[t]{2}{*}{66.60} & \multirow[t]{2}{*}{14.415} & & \\
\hline & Group B & Abduction & & & & \\
\hline & Group A & post MUSCLE & \multirow[t]{2}{*}{52.00} & \multirow[t]{2}{*}{18.908} & & \\
\hline & & STRENGTH & & & & \\
\hline \multirow[t]{5}{*}{2} & & & & & 0.065 & $0.950 \mathrm{NS}$ \\
\hline & & Post MUSCLE & \multirow[t]{2}{*}{52.80} & \multirow[t]{2}{*}{19.930} & & \\
\hline & Group B & STRENGTH & & & & \\
\hline & \multirow[t]{2}{*}{ Group A } & Post & \multirow[t]{2}{*}{3.60} & \multirow[t]{2}{*}{0.548} & & \\
\hline & & MUSCLE POWER & & & & \\
\hline 3 & & & & & 0.577 & $0.580 \mathrm{NS}$ \\
\hline
\end{tabular}




\begin{tabular}{|c|c|c|c|c|c|c|}
\hline & Group B & Post MUSCLE POWER & 3.40 & 0.548 & & \\
\hline & & & & & \\
\hline $\mathbf{4}$ & \multirow{2}{*}{ Group A } & Post & 5.00 & 0.707 & & \\
\cline { 1 - 3 } & & NPRS SCORE & & & &. \\
\hline & & & & & 1.372 & $0.207 \mathrm{NS}$ \\
\hline & Group B & Post NPRS SCORE & 4.20 & 1.095 & & \\
\hline & & Post & 25.628 & 12.794 & & \\
\hline $\mathbf{5}$ & Group A & SPADI SCORE & & & & \multirow{2}{*}{$0.597 \mathrm{NS}$} \\
\hline & & & & & 0.551 & \\
\hline
\end{tabular}

$\mathrm{P}>0.05$

This table shows no Statistical Significant difference in the values of muscle Strength, muscle Power, shoulder abduction, Numerical Pain Rating scale, and shoulder pain and disability index score between Group A and Group B subjects.

\section{Results:-}

According To Table 1:- shows there was no Statistical Significance difference between Pre and Post test among ROM Shoulder Abduction, MUSCLE Strength, MUSCLE Power and NPRS Score among Group A at 95\% (P > 0.05). There is a statistical significance difference between pre and post test values of Shoulder Pain And Disability Index(SPADI) Score among Group A at $95 \%(\mathrm{P}<0.05)$.

According To Table 2:-

shows that there is no statistical difference between pre and post test of Muscle strength and muscle power among Group-B Subjects treated with Eccentric and wax 95\% $(\mathrm{P}>0.05)$. There is a statistical significance difference between pre and post testamong the ROM Shoulder Abduction, Numeric pain rating scale (NPRS) Score and Shoulder Pain And Disability Index(SPADI).Score in Group B at $95 \%(\mathrm{P}<0.05)$

According To Table 3:-

shows there was no Statistical Significance difference between Post tests among ROM Shoulder Abduction, MUSCLE Strength, MUSCLE Power ,NPRS Score and Shoulder Pain And Disability Index(SPADI among Group A Treated with concentric exercise and wax, and Group B Treated with eccentric exercise and wax at $95 \%(\mathrm{P}>$ $0.05)$.

\section{Discussion:-}

The scapula plays an important role in shoulder impingement syndrome. It is a wide, flat bone lying on the posterior thoracic wall that provides an attachment for three different groups of muscles. The intrinsic muscles of the scapula include the muscles of the rotator cuff- the subscapularis, infraspinatus, teres minor and supraspinatus. These muscles attach to the surface of the scapula and are responsible for the internal and external rotation of the glenohumeral joint, along with humeral abduction. The extrinsic muscles include the biceps, triceps, and deltoid muscles and attach to the coracoid process and supra glenoid tubercle of the scapula, infra glenoid tubercle of the scapula, and spine of the scapula. These muscles are responsible for several actions of the glenohumeral joint. The third group, which is mainly responsible for stabilization and rotation of the scapula, consists of the trapezius, serratus anterior, levator scapulae, and rhomboid muscles and attach to the medial, superior, and inferior borders of the scapula. Each of these muscles has their own role in proper shoulder function and must be in balance with each other in order to avoid shoulder pathology. Abnormal scapular function is called scapular dyskinesis. One action the scapula performs during a throwing or serving motion is elevation of the acromion process in order to avoid impingement of the rotator cuff tendons. If the scapula fails to properly elevate the acromion, impingement may occur during the cocking and acceleration phase of an overhead activity. The two muscles most commonly inhibited during this first part of an overhead motion are the serratus anterior and the lower trapezius. These two muscles act as a force couple within the glenohumeral joint to properly elevate the acromion process, and if a muscle imbalance exists, shoulder impingement may develop. The aforementioned studies only assessed pain intensity and selfreported functional level, but did not assess strength or Range of Motion and strength, power. The results of this study reveals that there is no significant difference in Numerical pain Rating Scale, Range of Motion, Muscle strength and Muscle power in Group A(Concentric group) but in Group B there was a statistically significant 
differences in (Eccentric group) between the Group A and Group B in NPRS scores, indicating that eccentric-based exercises were more effective than concentric-based exercises for treating patients with Subacromial impingement syndrome. Curwin and Stanish et al The mechanism of action for eccentric exercise on tendinosis remains speculative, but some interesting possibilities do exist. In their pioneering work, proposed that poor neuromuscular control during muscle action, especially during eccentric muscle action, may overload the tendon with high impulses. Hence, retraining the neuromuscular system to accommodate to eccentric loads may reduce excessive forces on the tendon. Although data demonstrate differences in movement patterns between patients with tendinosis and uninjured controls, whether eccentric training normalizes movement and loading patterns of patients with symptomatic tendinosis is unknown. Eccentric exercise may enhance the mechanical properties of the degenerative tendon. Weight-bearing exercise has long been known to enhance the mechanical properties of tendons by increasing blood flow, oxygen uptake, metabolic rate, collagen degradation, and collagen synthesis in healthy tendons. Unfortunately, little information is available about how exercise affects tendinosis and how eccentric exercise differs from other types of exercise with respect to the structural basis of the tendon. Recently, Langberg et al found that 12 weeks of eccentric exercise reduced tendinosis-related pain and stimulated collagen synthesis but did not change the rate of collagen degradation. This finding suggests that eccentric exercise may increase the mass of the tendon because of the enhanced deposition of type I collagen. The stimulation of type I collagen production may be of particular benefit because fibroblasts from areas of tendinosis normally synthesize a greater proportion of mechanically inferior type III collagen than their healthy counterparts. Thus, eccentric exercise may serve to strengthen the tendon and protect it from subsequent overuse. It has been theorized that eccentric exercise may inhibit the production of agents responsible for producing pain in tendinosis. Chemical agents associated with symptomatic tendinosis include substance $\mathrm{P}$, glutamate, and calcitonin gene-related peptide but exclude prostaglandin E 2. Although these neuropeptides may be responsible for tendinosis pain, patients treated with eccentric exercise demonstrated no change in tendinous glutamate levels despite reduced pain. SPADI scores are significant in both the groups concentric ( $p$ value - 0.001) and eccentric ( $p$ value -0.002) Maenhout et al, reported better shoulder abduction strength in the eccentric group after 12 weeks of intervention. However, similar to the findings of the current study, Maenhout et al did not find a significant difference in functional scores using the Shoulder Pain and Disability Index (SPADI). The difference in exercise resistance level and number of different eccentric exercises performed. Range of Motion is statistically significant in Group B than in Group A because the eccentric activities is lengthening of muscle fibre. According to curmin and stanish et al

Eccentric exercise may enhance the mechanical properties of the degenerative tendon. Weight-bearing exercise has long been known to enhance the mechanical properties of tendons by increasing blood flow, oxygen uptake, metabolic rate, collagen degradation, and collagen synthesis in healthy tendons. But on comparing the post test values between Group A subjects trained with concentric exercises and Group B subjects trained with Eccentric exercises, the results of this study shows that there is no significant difference in strength, range of motion, NPRS scores, muscle power This might have influenced the results making its statistically insignificant but clinically concentric training was found more comfortable for the patients and also the increase in SPADI score as less compared to eccentric training but this statistically proven due to the less sample size and taken in a shorter duration .As far as study is concerned, long term belief of concentric training was clinically insignificant and eccentric training was found to have more benefits in patients. These findings agree with the findings of the other authors who used resistance exercise in the treatment of Subacromial impingement syndrome that resulted in improved function.

\section{Conclusion:-}

The study was done to compare the Pain, Range of motion, Power, strength, functional activities, variables during concentric and eccentric exercises on Sub acromial impingement syndrome .From the results of the study, it is concluded that there is no statistically significant difference in the above variables during concentric and eccentric exercises intervention in sub acromial impingement syndrome.

\section{References:-}

1. van der Windt DA, Koes BW, De Jong BA, et al. Shoulder disorders in general practice:

2. Incidence, patient characteristics, and management. Ann. Rheum Dis. 1995;54(12):959-964

3. Higbie EJ, Cureton KJ, Warren GL 3rd, et al. Effects of concentric and eccentric training on muscle strength, cross-sectional area, and neural activation. J. Appl.Physiol. (Bethesda, Md.: 1985), 1996;81(5):2173-2181

4. Bast SC, Vangsness CT Jr, Takemura J, et al. The effects of concentric versus eccentric isokinetic strength training of the rotator cuff in the plane of the scapula at various speeds. 
5. Bulletin (Hospital for Joint Diseases (New York, N.Y.)), 1998;57(3):139-144.

6. Conroy DE, Hayes KW. The effect of joint mobilization as a component of comprehensive treatment for primary shoulder impingement syndrome. J. Orthop Sports Phys. Ther. 1998;28(1): 3-14.

7. Bang MD, Deyle GD. Comparison of supervised exercise with and without manual physical therapy for patients with shoulder impingement syndrome. J. Orthop Sports Phys. Ther. 2000;30(3):126-137

8. Dinnes J, Loveman E, McIntyre, et al. The effectiveness of diagnostic tests for the assessment of shoulder pain due to soft tissue disorders: A systematic review. Health Technol.Assess. 2003;7(29):iii-1-166.

9. Ludewig PM. Borstad JD. Effects of a home exercise programme on shoulder pain and functional status in construction workers. Occup.Environ Med. 2003;60(11):841-849

10. Green S, Buchbinder R, Hetrick S. Physiotherapy interventions for shoulder pain. Cochrane Database Syst. Rev. (Online).2003;(2):CD004258.

11. Am Rhew Dis..Analysing of four shoulder-specific Questionaries in primary care.2004:63:1293-1299

12. Trampas A, Kitsios A. Exercise and manual therapy for the treatment of impingement syndrome of the shoulder: A systematic review. Physical Therapy Reviews. 2006;11(2):125-142.

13. Senbursa G, Baltaci G, Atay A. Comparison of conservative treatment with and without manual physical therapy for patients with shoulder impingement syndrome: A prospective, randomized clinical trial. Knee Surg.Sports Traumatol. Arthrosc.: 2007;15(7):915-921.

14. Heinemeier KM, Olesen JL, Haddad F, et al. Expression of collagen and related growth factors in rat tendon and skeletal muscle in response to specifi c contraction types. J. Physiol., 2007;582(Pt 3):1303-1316

15. Kingma JJ, de Knikker R, Wittink HM, et al. Eccentric overload training in patients with chronic achilles tendinopathy: A systematic review. Brit J.Sport Med. 2007;41(6):e3.

16. Lombardi I, Jr, Magri AG, Fleury AM, et al. Progressive resistance training in patients with shoulder impingement syndrome: A randomized controlled trial. Arthritis Rheum. 2008;59(5):615-622

17. Nakamura K, Kitaoka K, Tomita K. Effect of eccentric exercise on the healing process of injured patellar tendon in rats. J. Orthop. Sci., 2008;13(4): 371-378.

18. Andres BM, Murrell GA. Treatment of tendinopathy: What works, what does not, and what is on the horizon. Clin. Orthop Relat. R. 2008;466(7):1539-15. 